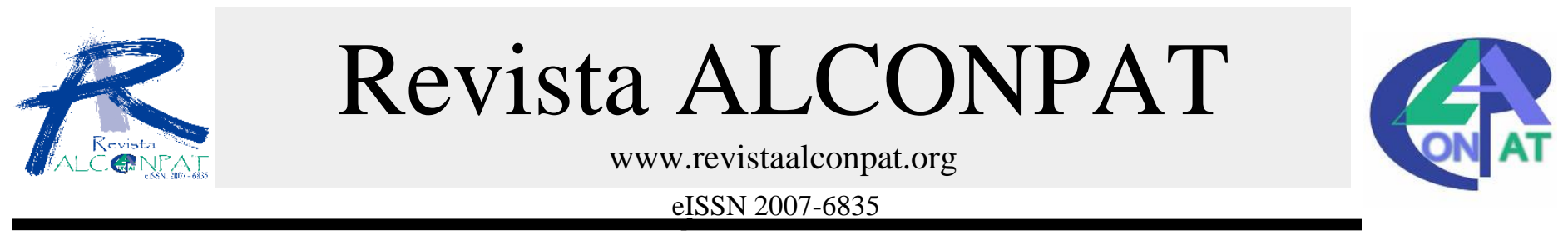

Revista de la Asociación Latinoamericana de Control de Calidad, Patología y Recuperación de la Construcción

\title{
Análisis crítico sobre el ensayo m-k de forjados de chapa colaborante
}

\author{
L. Echevarría ${ }^{1}$, J. P. Gutiérrez ${ }^{1}$
}

${ }^{1}$ Instituto de Ciencias de la Construcción Eduardo Torroja. Consejo Superior de Investigaciones Científicas (IETcc-CSIC). C/Serrano Galvache, $n^{\circ} 4$, 28033. Madrid. España.

Información del artículo

DOI:

http://dx.doi.org/10.21041/ra.v2

$\underline{i 3.36}$

Artículo recibido el 25 de Junio de 2012, revisado bajo las políticas de publicación de la Revista ALCONPAT y aceptado el 07 de Septiembre de 2012. Cualquier discusión, incluyendo la réplica de los autores se publicará en el segundo número del año 2013 siempre y cuando la información se reciba antes del cierre del primer número del año 2013

\section{(C) 2012 ALCONPAT Internacional}

Información Legal

Revista ALCONPAT, Año 2, No. 3 , Septiembre - Diciembre 2012, es una publicación cuatrimestral de la Asociación Latinoamericana de Control de Calidad, Patología y Recuperación de la Construcción, Patología y Recuperación de la Construcción, Internacional, A.C., Km. 6, antigua carre
Progreso, Mérida Yucatán, C.P. 97310 , Progreso, Mérida Yucatán, C.P. 97310 ,
Tel.5219997385893, alconpat.int@ @gmail.com, Página Web: www.alconpat.org

Editor responsable: Dr. Pedro Castro Borges. Reserva de derechos al uso exclusivo No.04 2013-011717330300-203, eISSN 2007-6835, ambos otorgados por el Instituto Nacional de Derecho de Autor. Responsable de la última actualización de este número, Unidad de Informática ALCONPAT, Ing. Elizabeth Sabido Maldonado, Km. 6, antigua carretera a Progreso, Mérida Yucatán, C.P. 97310 , fecha de publicación: 30 de septiembre de 2012

Las opiniones expresadas por los autores no necesariamente reflejan la postura del editor Queda totalmente prohibida la reproducción total o parcial de los contenidos e imágenes de la publicación sin previa autorización de la

ALCONPAT Internacional A.C.

\section{RESUMEN}

El fallo resistente de los forjados de chapa colaborante se suele producir por el deslizamiento longitudinal entre la chapa nervada de acero y el hormigón provocado por el esfuerzo rasante que se produce a consecuencia del cortante.

Puesto que no existe ninguna ecuación analítica que determine la resistencia del forjado frente a este esfuerzo a partir de la geometría de la chapa, ésta se obtiene a partir de ensayos, de los cuales el más empleado es el ensayo m-k, establecido por la AISI en 1967. Este ensayo tiene como objetivo la obtención de dos parámetros $\mathrm{m}$ y $\mathrm{k}$, que permiten evaluar mediante una fórmula semiempírica la resistencia del forjado frente a las tensiones rasantes.

El objetivo de este trabajo es poner de manifiesto cuáles son las limitaciones del ensayo m-k para forjados de chapa colaborante y señalar la información adicional que es capaz de proporcionar este ensayo.

Palabras Clave: forjado de chapa colaborante; ensayo m-k; rasante; análisis; adherencia.

\section{ABSTRACT}

The failure of the composite slab is usually produced by the longitudinal slip between the steel sheet and the concrete, which is formed by the interface shear due to vertical shear.

As there is no analytic equation that determines the resistance of the slab against this effort once given the geometry of the steel sheet, the resistance is obtained from tests, of which the most used is the m-k test, established by the AISI in 1967. This test is focused on the consecution of two parameters called $\mathrm{m}$ and $\mathrm{k}$, that allow us to evaluate the longitudinal shear resistance of the composite slab by using a semi-empirical formula.

The aim of this paper is to highlight the limitations of the $\mathrm{m}-\mathrm{k}$ test for composite slab and identify the additional information that this test can provide.

Keywords: composite slab; m-k test; longitudinal shear; analysis; chemical bond.

Autor de contacto: José Pedro Gutiérrez Jiménez (jpgutierrez@ietcc.csic.es) 
Revista ALCONPAT, Volumen 2, Número 3, Septiembre - Diciembre 2012, Páginas 174 - 181

\section{INTRODUCCIÓN}

Un forjado mixto de chapa colaborante consiste en una chapa nervada de acero conformada en frío, de espesor entre 0,75 y $1,25 \mathrm{~mm}$ y módulo de elasticidad cercano a los $350 \mathrm{MPa}$, que apoyada sobre las vigas de la estructura, ejerce las funciones de encofrado perdido autoportante y armadura de tracción del forjado, sobre la que se vierte el hormigón fresco durante el proceso constructivo, a modo de losa de compresión (Figura 1).

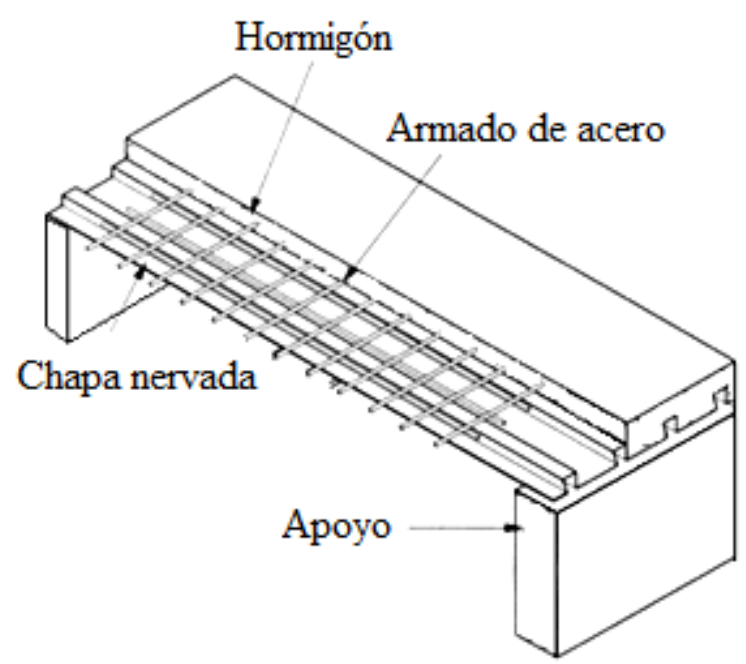

Figura 1. Partes de un forjado de chapa colaborante

Desde muy pronto se observó que el principal fallo resistente se produce por el deslizamiento longitudinal entre la chapa nervada y el hormigón provocado por el esfuerzo rasante (Bryla, 1967) que se genera en dicha sección a causa del cortante, es decir, por la pérdida de la conexión entre acero y hormigón (figura 1). Por este motivo, a la hora de proyectar este tipo de forjado, el proyectista debe realizar, además de las comprobaciones necesarias para cualquier tipo de forjado (flexión positiva y negativa, cortante, punzonamiento, etc.), una comprobación del forjado frente a esfuerzos rasantes.

Puesto que no existe ninguna fórmula analítica que determine la resistencia del forjado frente a este esfuerzo a partir de la geometría de la chapa, ésta se obtiene a partir de ensayos, de los cuales el más empleado es el ensayo $m$ - $k$, establecido por la AISI (American Iron and Steel Institute) en 1967. Este ensayo tiene como objetivo la obtención de dos parámetros $m$ - $k$, que permiten evaluar mediante la fórmula semiempírica (1) (fórmula empleada en el eurocódigo 4), u otras fórmulas similares, la resistencia del forjado frente a las tensiones rasantes.

$$
V_{l, R d}=b \cdot d_{p} \cdot\left(\frac{m \cdot A_{p}}{b \cdot L_{s}}+k\right) / \gamma_{v s}
$$

Donde $V_{l, R d}$ es el cortante máximo $(N), b$ es el ancho del forjado $(\mathrm{mm}), d_{p}$ es el canto $(\mathrm{mm}), A_{p}$ es el área de la chapa grecada $\left(\mathrm{mm}^{2}\right), m$ y $k$, son los dos parámetros que definen el comportamiento de la chapa frente a tensiones rasantes $(M P a), \gamma_{v s}$ es el coeficiente parcial de seguridad para el estado límite último, que tiene un valor recomendado de 1.25 según el 
eurocódigo 4 y $L_{s}(\mathrm{~mm})$ es la longitud de cortante, que se define como $L / 4$, para cargas uniformemente aplicadas en todo el vano y es igual para el caso de cargas puntuales, a la distancia del punto de aplicación de la carga al apoyo más cercano.

El objetivo de este trabajo es poner de manifiesto toda la información que proporciona el ensayo $m-k$, y destacar la existencia de ciertos datos útiles que se pueden obtener durante la realización de este ensayo y que pueden ser de mucha utilidad para el proyectista.

\section{PROCESO EXPERIMENTAL}

Se han realizado en el Instituto Eduardo Torroja de Ciencias de la Construcción todos los ensayos necesarios para establecer los parámetros $m$ y $k$ de un forjado mixto hormigonado con un hormigón convencional de 25,5 $\mathrm{MPa}$ de resistencia característica, siguiendo las características que se establecen a continuación.

\subsection{Disposición del ensayo}

El método $m-k$ consiste en un conjunto de ensayos a escala natural que se realizan para obtener los parámetros $m$ y $k$ que permiten estimar la resistencia a tensión rasante. Estos ensayos suelen ser realizados por las empresas fabricantes de las chapas grecadas para cada una de sus chapas, por lo que no es necesario realizar el ensayo para cada disposición del forjado. En concreto, el eurocódigo 4 (CEN. Eurocódigo 4) proporciona una serie de criterios para indicar cuando un ensayo es representativo de las demás disposiciones:

- Espesores mayores de chapa.

- Losas de mayor espesor del ensayado.

- Un hormigón con resistencia característica superior a $0.8 \cdot f_{c m}$, donde $f_{c m}$ es la resistencia media del hormigón de los ensayos.

- Para aceros con límite elástico superior a $0.8 \cdot f_{y m}$, donde $f_{y m}$ es el valor medio del límite elástico de las chapas ensayadas.

Estos criterios obligan al fabricante a realizar ensayos con losas pequeñas y de características resistentes inferiores o iguales a las que luego se empleen en obra, ya que una vez obtenidos los valores $m$ y $k$, estos sólo puedan ser utilizados para dimensionar forjados con mejores características.

Los ensayos se llevan a cabo en dos grupos de losas biapoyadas de distintas longitudes, a las que se le aplican dos líneas de carga transversales simétricas iguales, situadas a $L /{ }_{4} \mathrm{y} 3 / 4$. 


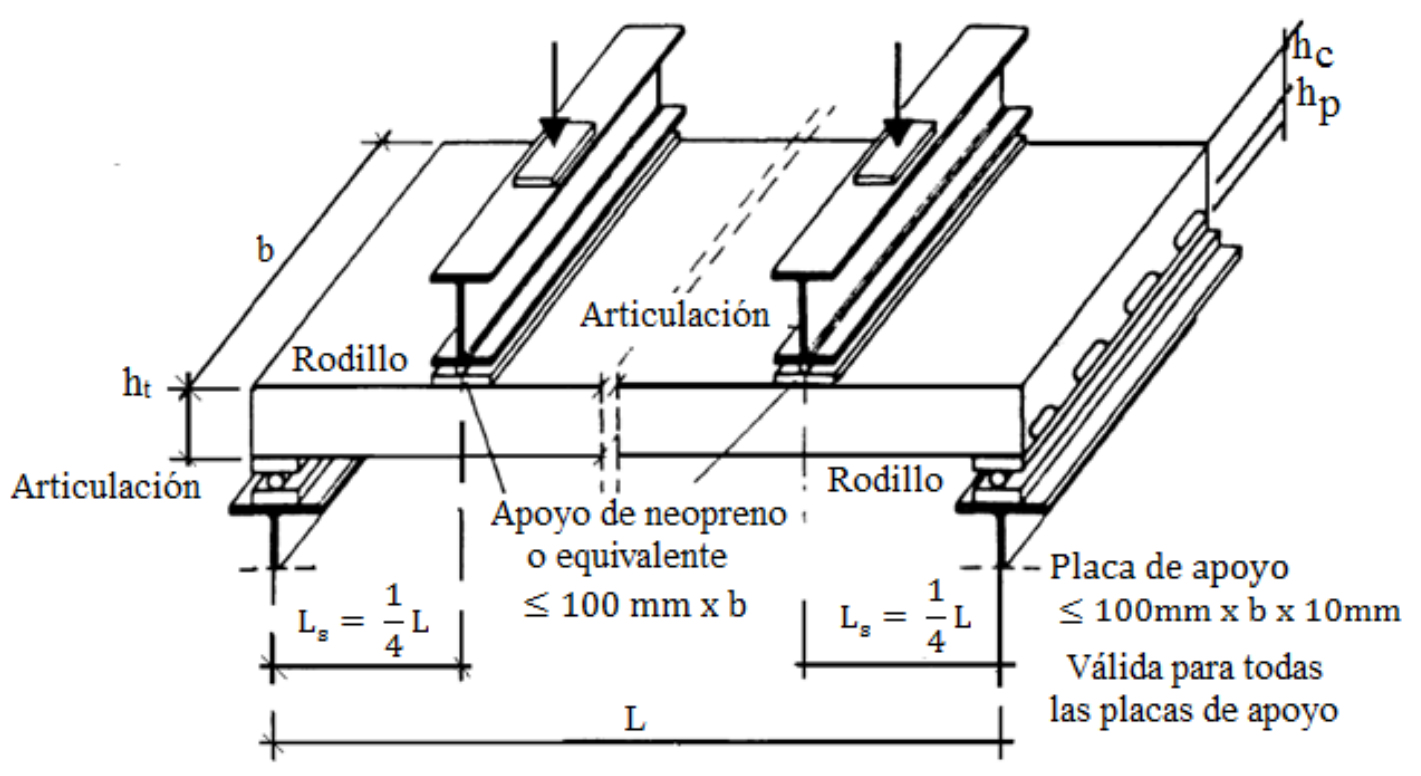

Figura 2. Configuración del ensayo $m-k$

El método comienza ensayando una probeta hasta rotura que se puede realizar en control de carga o en control de deformación. A partir de la carga de rotura de este primer ensayo, se realizan el resto de los ensayos con una carga cíclica inicial de 5000 ciclos. Los ciclos varían entre una carga mínima del $20 \%$ y un valor máximo del $60 \%$ de la carga de rotura de la primera probeta. Una vez realizada la primera parte del ensayo se continúa aumentando la carga hasta rotura.

\subsection{Explotación de resultados}

Se suelen realizar un total de 6 ensayos (dos grupos de tres ensayos, en los que cada grupo presenta una longitud de cortante distinta). A partir de la carga de rotura de los seis ensayos, se obtiene una recta, como está representado en la Figura 3.

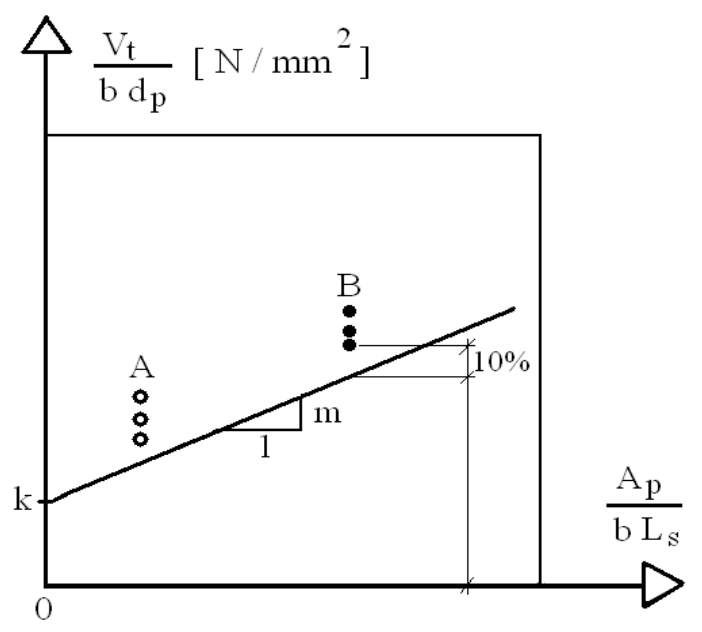

Figura 3. Obtención de los parámetros $m$ y $k$

Donde $V_{t}$ es el cortante obtenido de los ensayos (en Newton) 
Para obtener la recta $m-k$ se realiza el siguiente proceso:

- Se desechan los resultados que difieran del resto más del $10 \%$.

- Se reduce un $10 \%$ el valor del menor de los resultados de cada grupo.

- Con esos dos valores se establece una recta. La ordenada en el origen es el valor $k$, y la inclinación es $m$.

\section{RESULTADOS}

\subsection{Resistencia}

Pese a que existen tres solicitaciones básicas que producen el fallo en un forjado de chapa colaborante (tensión rasante, cortante y momento flector), la mayoría de dichos forjados fallan por tensiones rasantes. En la Figura 4 se muestra la resistencia de un forjado de chapa colaborante frente a las distintas solicitaciones cuando se le aplican unas cargas dispuestas como se indican en el apartado anterior.

También se incluye la resistencia frente a esfuerzo rasante como se indica en dos normativas, la del eurocódigo 4, explicada con anterioridad, y la de los British Standards (BSI. BS 5950-4, 1994), que sigue una fórmula ligeramente distinta a la del eurocódigo:

$$
V_{l, R d}=b \cdot d_{p} \cdot\left(\frac{m \cdot A_{p}}{b \cdot L_{s}}+k \sqrt{f_{c m}}\right) / \gamma_{v s}
$$

Donde $f_{c m}$ es la resistencia media del hormigón de la probeta cúbica.

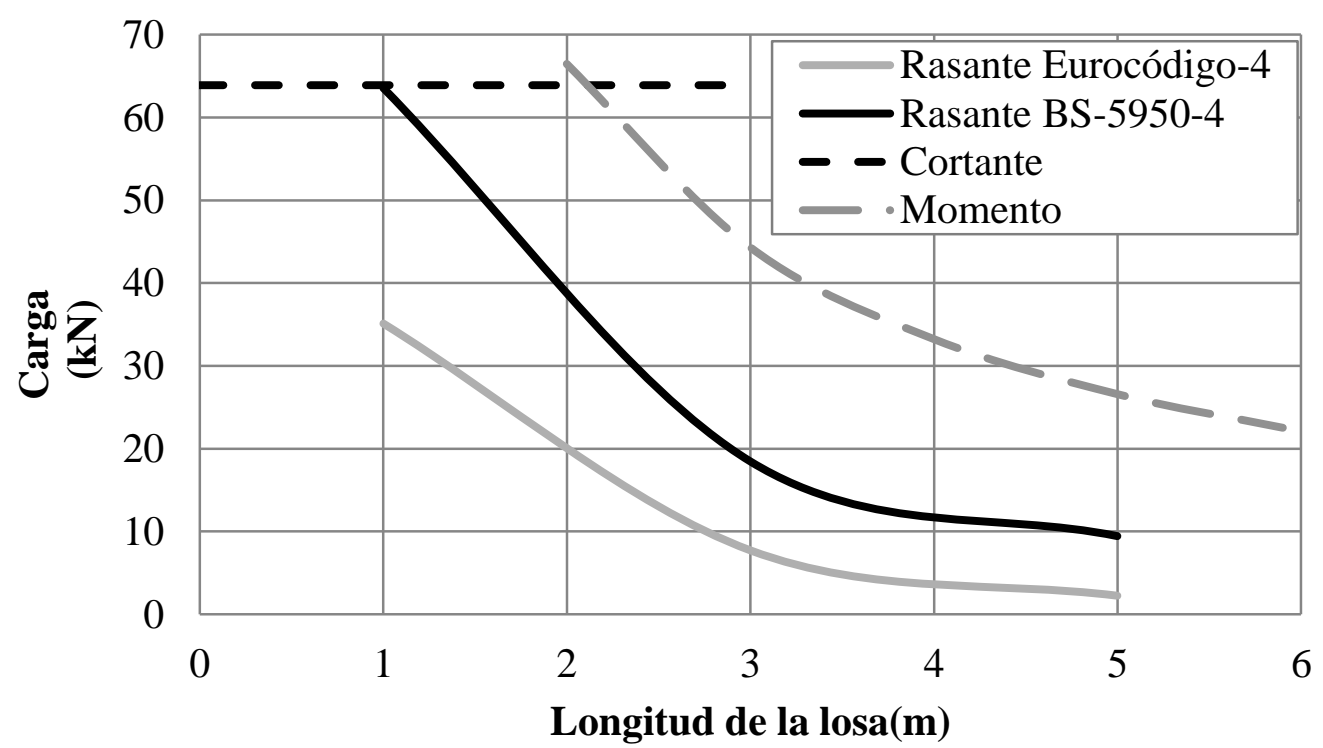

Figura 4. Resistencia de un forjado de chapa colaborante frente a distintas solicitaciones. 
Se puede observar que, para pequeñas luces, la rotura se produce debido al cortante, mientras que para luces mayores la rotura es siempre por rasante.

Destaca la gran diferencia entre el esfuerzo rasante máximo según el eurocódigo y la normativa británica, que se debe a que los parámetros $m$ y $k$ se establecen de manera distinta en la normativa británica cuando el parámetro $k$ es negativo, lo que conlleva a grandes diferencias, especialmente cuando la longitud de la losa es pequeña.

\subsection{Modos de resistencia}

Es importante conocer el comportamiento del forjado según se va cargando. Existen tres modos de resistencia, (adherencia química, interferencia mecánica de las embuticiones y anclajes mecánicos), cada uno de los cuales presenta una rigidez distinta.

Frente a pequeñas solicitaciones, la adherencia entre chapa y hormigón es total. Por este motivo, aparece una tensión rasante en la interfase entre acero y hormigón, que en este rango de cargas es soportada por la adherencia química entre ambos que se forma durante el fraguado.

Una vez superado el rasante máximo que es capaz de absorber la adherencia química, esta falla y en ese momento empiezan a trabajar las embuticiones o indentaciones que se le realizan a la chapa. Cuando se inicia el deslizamiento, las embuticiones impiden, por interferencia mecánica, que el hormigón siga deformándose, por lo que es necesario un aumento de las fuerzas para que la deformación crezca.

En la Figura 5 se muestran dos gráficas carga-flecha. La primera de ellas corresponde a la de un ensayo estático hasta rotura de una probeta que no ha sido sometida a ninguna carga antes del ensayo. La segunda representa el ensayo estático de una probeta que previamente había sido sometida a un ensayo dinámico de 5000 ciclos. Estos ensayos han sido realizados con una configuración análoga a la que muestra la Figura 2.

Como se puede observar en la Figura 5, la adherencia de la chapa hace que la rigidez del forjado sea mayor en la fase de carga inicial.

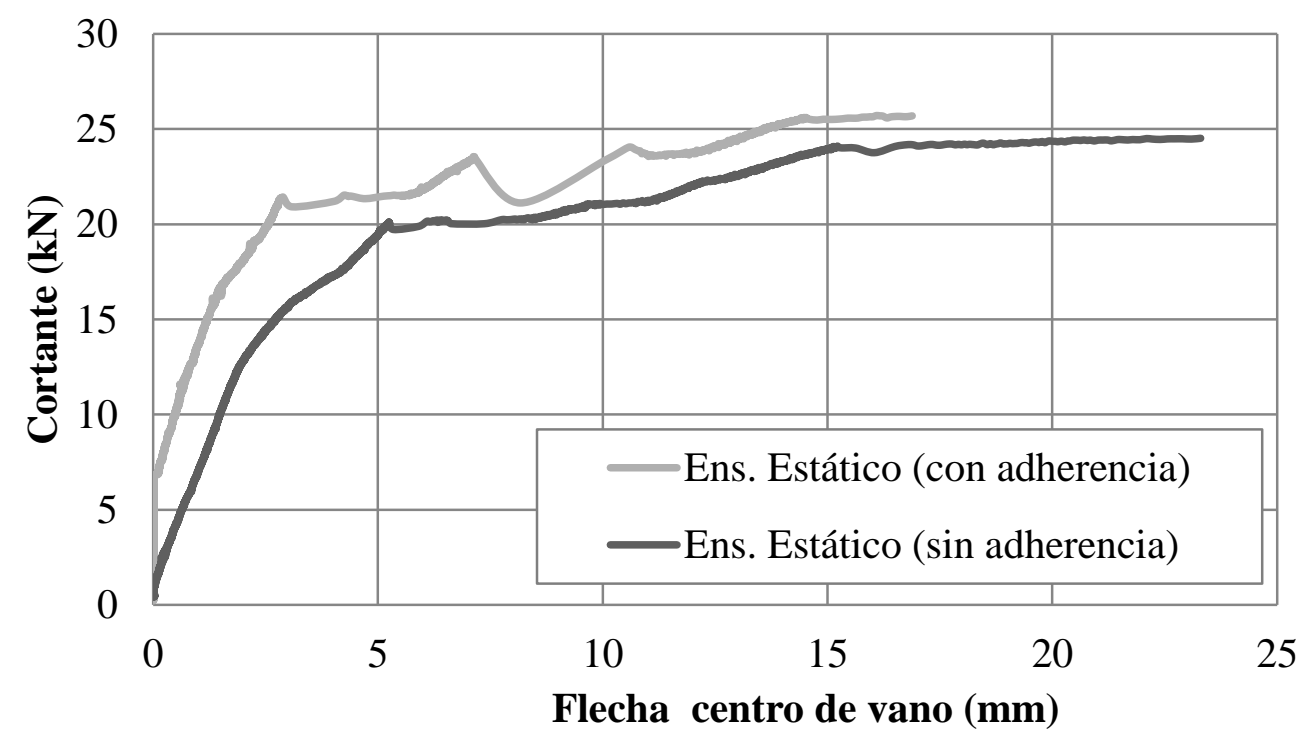

Figura 5. Gráfico Carga-flecha 
Por último, cuando la losa de hormigón se ha separado de la chapa (y por lo tanto ya no hay interferencia de las embuticiones), empezarían a funcionar los anclajes mecánicos de conexión con las vigas: cuando interesa que las vigas de la estructura metálica funcionen como mixtas, se aprovecha el forjado mixto como capa de compresión, y se incluyen conectadores en el ala superior del perfil metálico que posteriormente estarán embebidos en la losa.

\section{CONCLUSIONES}

A la hora de emplear el método $m-k$ para proyectar este tipo de forjados frente a esfuerzos rasantes, conviene tener en mente las siguientes características, que pueden obligar a modificar la estrategia constructiva:

- Existen muchos parámetros que intervienen en la resistencia a rasante del forjado, pero en la fórmula empleada en la mayor parte de las normativas actuales, sólo se tienen en cuenta parámetros geométricos.

- La normativa europea (principalmente el Eurocódigo 4) indica que el ensayo $m$ - $k$ debe realizarse sobre forjados que posean características resistentes iguales o inferiores a aquellos que se prevea que se van a emplear en obra. Este hecho, unido a que para obtener los parámetros $m$ y $k$ sólo se emplean los valores más bajos de cada una de las series de ensayos reducidos un $10 \%$ y a los distintos factores de seguridad, hacen que el cortante de cálculo del forjado sea muy inferior al obtenido en los ensayos. Este hecho ha sido confirmado por diversos autores, entre ellos (Hedaoo, 2012).

- El ensayo no da información sobre el importante aumento de resistencia frente a esfuerzos rasantes que se produce cuando se introduce armadura de refuerzo de negativos, como se explica en la bibliografía (Vicente, 2004). Tampoco permite evaluar el incremento de resistencia que produce la introducción de conectadores en la estructura.

- El ensayo tampoco da información sobre la carga a la que se produce el primer deslizamiento entre la chapa y el hormigón. Este debería ser un parámetro muy importante a la hora de proyectar un forjado de este tipo, ya que la estructura debería ser proyectada de manera que la carga de servicio fuera inferior a la carga de primer deslizamiento, aunque la normativa no obliga a ello.

- El principal motivo para incluir en el ensayo $m-k$ una carga cíclica antes de la realización del ensayo estático, es para que en este ensayo no intervenga la adherencia entre el acero y el hormigón, lo que hace disminuir la carga de primer deslizamiento y aumentar la deformación en rotura (Nagy, 1998).

- Conviene recordar que, pese al uso extendido de hormigones ligeros junto a chapas nervadas, este hace que la carga de primer deslizamiento disminuya, como se indica en la referencia bibliográfica (Urríes, 1989).

En resumen, aunque el método $m-k$ es un método muy práctico para la estimación de la resistencia frente a esfuerzos rasantes de un forjado de chapa colaborante, es aconsejable no emplear únicamente los parámetros $m-k$ que suministra el fabricante de la chapa, ya que el ensayo realizado por el fabricante corresponde a la configuración pésima del forjado. Es conveniente, para obras de suficiente entidad, elaborar nuestros propios ensayos, obteniendo además otra información relevante, como la carga de primer corrimiento entre la chapa y el hormigón que puede ayudar al proyectista a dimensionar el forjado frente a cargas de servicio. 
Revista ALCONPAT, Volumen 2, Número 3, Septiembre - Diciembre 2012, Páginas 174 - 181

\section{AGRADECIMIENTOS}

Este trabajo se ha desarrollado dentro del proyecto Intramural 201060E118 "Investigación de hormigones especiales avanzados para aplicaciones estructurales en ingeniería y arquitectura" financiado por el Consejo Superior de Investigaciones Científicas (CSIC).

\section{REFERENCIAS}

Bryla S. (1967), The composte effect of profiled steel plate and concrete in steel deck slabs. Acier Stahl Steel. Centre belgo-luxembourgeois d'information de l'acier. 32: pp 469.

BSI. BS 5950-4:1994. (1994), Structural use of steelwork in building. Code of practice for design of composite slabs with profiled steel sheeting.

CEN. Eurocódigo 4. Proyecto de estructuras mixtas de hormigón y acero. Parte 1-1: Reglas generales y reglas para edificación

Hedaoo N.A., Gupta L.M., Ronghe G.N. (2012), Design of composite slabs with proflied Steel decking: a comparison between experimental and analytical studies. Journal of Advanced Structural Engineering, 4,1.

Nagy Z.V., Szatmary I. (1998), Composite slab design. in: $2^{\text {nd }}$ Int PhD Symposium in Civil Engineering, Budapest, (Hungary)

Urríes J. J. (1989), Estudio experimental del comportamiento a flexión: tensiones rasantes y deformaciones de forjados compuestos de chapa y hormigones normales o ligeros. Tesis doctoral, Universidad Politécnica de Madrid.

Vicente R. (2004), Redistribución de esfuerzos en forjados de chapa nervada y hormigón continuos. Tesis doctoral, Universidad Politécnica de Madrid. 